\title{
BRITAIN'S COAL AND ITS FUTURE
}

$\mathrm{T}$ HE pace at which the material conditions of civilization are changing at the present time is unique in recorded history. Prof. Arnold Toynbee has contended that throughout the 5,000 years up to the past century these conditions, and the human outlook, remained fundamentally the same. But the rapid acceleration that began with the industrial revolution is now so far-reaching that it may herald a change in kind rather than of degree in the affairs of man kind; accompanied, it is to be hoped, by an incressed capacity for understanding and controlling the new environment. Though this general picture is true only of the industrial nations, none can long continue unaffected whether it participates in the process of industrialization or not. Prof. P. M. S. Blackett, in his recent presidential address to the British Associa. tion, has suggested that an investment of about $£ 1$ per head of population per annum is required initially to enable a society to 'take off' in this sense and gather the necessary momentum.

Nowhere is this acceleration more apparent than in the basic activities of fuel production and consumption. Industry has developed chiefly on energy from coal over some 200 years; oil has become important during the past forty years and nuclear energy is providing the latest example of repid growth. Other sources of energy have been, and are likely to remain, relatively unimportant in the broad picture. Oil has natural advantages, such as its convenience in use whether in the mobile internal combustion engine or as furnace fuel; and, in addition to its energy value, the demend for certain fractions as lubricants is by no means negligible. It is thus the cosl industry that may be most affected by the changing relative importance of these three sources of energy.

There is considerable misconception about the likely effects of these changes within the present century ; the quantity of coal used is very great, and nuclear energy, however rapidly developed, seems unlikely to shoulder a major part of Britain's power load before the final decades. Recent authoritative forecasts have predicted that the use of coal in the United States may be at least doubled over the next twenty years, though ultimately there may be some decline in consumption. In Britain, the change is unlikely to be spectacular, but an increase is to be expected in the immediate future. The large uncertainties that necessarily attend even the most careful attempts to foresee the overall trends and the detailed shifts in the modes of coal consumption thus pose many problems, not least to those responsible for both long-and short-term research on coal utilization.

It was in relation to this background that Dr. J. Bronowski, director of the Coal Resesirch Establishment of the National Coal Board, delivered to the Royal Institute of Chemistry the tenth Delton Lecture, entitled "Coal and Coal Chemicals in the National Economy", at the Manchester Town Hall on October 25. The large audience comprised, as well as scientists, a wide cross-section of the public led by the Lord Mayor; and a well-designed exhibi- tion relevant to the subject was arranged in the nearby public library by the Institute and the National Coal Board with the support of other organizations.

Dr. Bronowski's lecture consisted of a thoughtful analysis of trends in the material basis of life with special reference to fuel, their extrapolation into the future, and their bearing on current research policy. $\mathrm{He}$ demonstrated that the standard of living of a society is related in precise detail to its degree of mechanization ; as measures of mechanization, steel and energy consumption per unit of population, representing respectively indices of material being processed and of energy used in processing it, are both satisfactory. For reasons that are obvious, food consumption as a messure of standard of living tends to rise to a maximum, whereas the rate of increase of income with increase in mechanization shows no slackening. The position of the United Kingdom on the food-graph lies near the maximum, whereas on the income curves it lies well below that of the United States and Canada, though it is high among the European countries. With esch additional ton of coal or its equivalent used annually by the individual, the average income rises by approximately $£ 60$ a year.

The acceleration in energy consumption is well illustrated by the fact that half the coal used in the history of mankind has been consumed in the past twenty-five years, and half the petroleum in the past ten. Coal had traditionally been used in two ways: to provide energy, and to produce coke for steelmaking-the latter a crude chemical use.

In Great Britain, only two forms of coal consump. tion are still increasing rapidly : electricity generation by about 80 per cent over the past ten years and metallurgical coke production by about 60 per cent; other uses are for the most part either falling, stationary, or if still increasing, decelerating rapidly. Coal production is inflexible, the increase over the whole world since 1910 having been only 40 per cent, smaller than the increase in population. Considering the two accelerating demands in this context, electricity production at its present rate of increase cannot for long continue to be based solely on cosl ; demand could not be met, and to attempt it would be inimical to the best use of the three main fuels. The nuclear fuels have no other large-scale application, but coal has its considerable chemical value. Moreover, the contribution of fuel to the total cost of manufactured goods is falling. This is due to the general shift from heavy towards light industry in which skill and therefore labour costs are relatively more important. A parallel tendency is from solid fuels towards the more flexible fluid forms, oil and gas. Dr. Bronowski emphasized that, owing to the exhaustion of the older seams and increased mechanization, the trends in the types of coal available are towards the following: coals yielding more volatile matter on heating but of less value in coke making; an increased proportion of small coal; and coals of increased ash content. Such lower-grade coals should 
be regarded progressively, in planning for the future, as raw material for making refined fuels and chemicals rather than as fuels per se.

The chemical by-products of coal carbonization now of greatest importance are benzene, naphthalene and phenols; these are linked with gas and coke production. From present tendencies, Dr. Bronowski estimated a need in 1975 for 50 million tons [an estimate perhaps on the high side] of coal to make metallurgical coke, a development that will make available considerably larger amounts of these chemicals. Thus the only use of coal likely to expand considerably will - in opposition to the pattern of production-demand selectively the better classes of coking coal unless the range of coals that can be used for this purpose can be widened-an important research objective. Even with this increase, the production from coal of the three chemicals mentioned will probably be inadequate-barely half the estimated needs of their users. Moreover, the coke oven is a most expensive plant requiring a capital investment of $£ 7.7$ for each $£ 1$ of value added in the product, as compared with $£ 2 \cdot 2$ average in industry. The remainder of the lecture was therefore concerned with alternative methods of producing chemicals and coke or coke substitutes from a wider range of coals.

The chemicel structure of oil is more suited to flexibility in the production of raw materials for chemical industry than that of coal; moreover, research in the pest has been pursued more energetically in the oil industry. Nevertheless, the constitution of coal gives it a natural advantage for the production of aromatic chemicals; and though the hydrogen/ carbon ratio in coal is low, carbonization leads to disproportionation reactions, yielding volatile products of higher ratio and a carbonaceous residue. Fluid-bed conditions are more favourable to high yields of liquid producta than those in the fixed bed of a coke oven, which favour secondary cracking of the products. The former type of process converts coal to a powdered char, with good yields of tar, and a rich gas; these novel tars are less suited to the current market for tar chemicals, though there is a low-price outlet in the expanding market for coal-tar fuels. Dr. Bronowski mentioned the processes, being developed at the National Coal Board's Coal Research Establishment, designed to convert such chars by briquetting to smokeless fuels for domestic use [see also Sir Charles Ellis, Nature, 175, 274; 1955].

Such processes are envisaged only as an interim measure, since the demand for solid smokeless fuels may well prove ephemeral. The next step would be gasification of the char, made as described above by fluidized carbonization with production from the tar of medium oil. The gasification stage could produce alternatively a rich gas for heating or a synthesis gas for production of oil-especially the gas and Diesel oils increasingly in demand as fuels rather than light oil of high octane number, previously the main objective of the Fischer-Tropsch process. Some of the simplest and most flexible chemical raw materials now made from petroleum, such as the olefines, could also then be made as by-products during production of oil from coal. Another potential use for the char is for production of calcium carbide simultaneously with gasification at high temperature using oxygen.

Looking still farther ahead to the end of the century, the possible availability of electricity at very low cost from nuclear reactors might make available cheap electrolytic hydrogen, so that the question of direct hydrogenation of coal to fuel oil, at present uneconomic owing to the high cost of hydrogen and power, might be reopened.

Dr. Bronowaki concluded by emphasizing that these were his personsl views on the future of coal. In brief, the post-war energy famine is ending; the industrial energy demand will ultimately be carried chiefly by atomic energy; small and high-volatile coal thus set free could be used for making solid smokeless fuels, and later, fluid fuels and chemicals.

In broad perspective, Dr. Bronowski's review of trends and portents corresponds closely with views increasingly coming to be accepted in Britain, and indeed in other European countries (see, for example, D. W. van Krevelen, Chem. and Indust., 546 ; 1957). It will be conceded that there is likely to be an important shift in the use of coal within a few decades towards gasification and the production of oil. Opinions may differ, however, as to the advantage of a twostage process, in which fluidized carbonization of coal precedes gasification of the char, over gasification of the coel in a single stage; this will depend pertly on the commercial value of the tar produced by the first method. It may also be expected that for many years an appreciable amount of small cosl of high ash content will be burnt in boiler plant, increasingly automatic, to provide heat and power for small industries. The extent of this will be affected by the siting of industry : for much of the heat inevitably wasted in a nuclear power station could ultimately be used as process heat in neighbouring factories. A large-scale outlet for higher-grade waste heat might, in fact, be provided by the gasification of coal or char, as suggested especially in the United States; the external source of heat would lead to many economies if it could be provided at not less than $900^{\circ} \mathrm{C}$., to maintain an endothermic reaction between carbon and steam. The prospects of success appear, however, to be small (see J. V. Dunworth, "The Future of Nuclear Power", Inst. Gas Eng. Copyright Publ. No. 513; 1957).

One other point should be mentioned : not only is the coke oven, as Dr. Bronowski stated, a most expensive plant ; the whole present sequence of steel making, using coke oven, blast furnace and openhoarth furnace, is costly and indirect, since it embodies three major stages and excess carbon introduced in the second has to be removed in the third (though for making special steels retention of this stage in some form would probably be necessary). It is quite possible that a successful single-stage process (see Sir Charles Goodeve, Advanc. Sci., 13, 23 ; 1956) might be developed before the end of the century; and if such a process proved effective and economic on an industrial scale it would seem likely that from that time onward only sufficient coke ovens to maintain supplies of foundry coke might be replaced. Their normal life being of the order of twenty years, one must envisage a possibility-no more at present -that the demand for metallurgical coking coals might then fall to a small fraction of its maximum level within some twenty years. Whether this will happen, and when, will determine whether a shortage (other than local) of coking cosls is likely to develop, and therefore the importance of research-necessarily in the immediate future - on the production of metal. lurgical coke from cosls at present unsuitable. In the writer's judgment, such research should be continued but regarded as an urgent and possibly short-term activity. I. G. C. DRYDEN 